\title{
ENHANCEMENT OF DYE ABSORPTION OF COTTON FABRIC THROUGH OPTIMIZATION OF BIOPOLYMER TREATMENT
}

\author{
MONA VERMA, NEHA GAHLOT, ${ }^{*}$ SAROJ S. J. SINGH and NEELAM M. ROSE \\ Department of Textile and Apparel Design, I.C. College of Home Science, \\ Chaudhary Charan Singh Haryana Agricultural University, \\ Hisar, India \\ "KVK, Jalore, Agriculture University Jodhpur, Rajsthan, India \\ \Corresponding author: Mona Verma, mona.verma35057@gmail.com
}

Received April 22, 2020

\begin{abstract}
Environmental pressure is pushing towards the 'green' alternatives to synthetic or petro-chemically derived products. Biopolymers are replacement materials suitable for different chemical processes. The surface modification of textile fibres using biopolymers is considered as the best route for modern textile treatments, to minimize the generation of wastewater containing salts, unfixed dye and other chemicals, which may affect the environment and human health. To avoid these problems, the pretreatment of cotton with biopolymers is a safe option in eco-friendly dyeing. In the present work, chitosan was selected for application on cotton textile for improving its dyeing efficiency with natural dye (onion skin). Chitosan is a versatile polycationic polysaccharide possessing hydroxyl and amino functional groups, which can easily be fabricated with desired functional properties. The chitosan treatment was standardized on the basis of dyeing properties, such as percent dye absorption, colour strength (K/S) and wash fastness. When the chitosan treatment was applied with optimized parameters, it was found that the chitosan treated onion skin dyed fabric showed higher dye absorption (66.17\%), colour strength (16.52) and wash fastness rating than the alum treated dyed fabric. Thus, the chitosan treatment enhanced the dyeing properties of cotton fabric towards the application of natural dye (onion skin), without using any metallic salt. To conclude, the chitosan treatment is a safe and environmentally benign route to improve the natural dye absorption of cotton fabrics.
\end{abstract}

Keywords: biopolymer, chitosan, cotton, natural dye, environment

\section{INTRODUCTION}

Today, when the world is facing threats of destruction because of contamination with toxic synthetic chemicals, environmental awareness should be the major focus. Here lies the relevance of reviving the art of dyeing with 'natural colorants' or 'natural dyes'. 'The technological development has gradually led to complex dyeing processes using synthetic dyeing practices. Presently, there is an excessive use of synthetic dyes, estimated at around 10,000,000 tons per annum, the production and application of which release vast amounts of waste and unfixed colorants, causing serious health hazards and disturbing the eco-balance of nature. ${ }^{2}$

Natural dyes have been proved to have better biodegradability than synthetic ones, being also eco-friendly, non-toxic and non-allergenic, as they are obtained from animals, plants, trees or vegetable matters, without chemical processes, and producing very uncommon, soothing and soft shades as compared to synthetic dyes. ${ }^{3}$ A major hurdle in using natural dyes is the serious lack of scientific data required for their successful application on textiles. Most of the researchers working in this area have reported very general information on types of shades/colour fastness properties, while the complete profile of their chemical nature, standard dyeing procedures and colour properties still remain to be elucidated. ${ }^{1}$ Reproducibility, inadequate availability, cost efficiency, inadequate degree of fixation, and poor colour fastness properties are common discernable drawbacks of natural dyes. ${ }^{4,5}$ The attempts to overcome these problems have been 
mainly focused on the use of metallic salts as mordants. ${ }^{6}$ Commonly used mordants are aluminum potassium sulfate, stannous chloride, ferrous sulfate and copper sulfate. ${ }^{7}$ Although metallic mordants are effective, they are environmental pollutants, hence not desirable. ${ }^{8}$ As the world becomes more ecologically conscious, there is greater need today to revive the tradition of natural dyeing with improved techniques and to develop innovative biomaterials as an alternative to hazardous metallic salt mordants.

The dyeing of cotton with natural dyes using biocompatible and biodegradable modification agents, such as chitosan and cyclodextrin, can be a cost-effective, environmentally friendly approach to be used in the dyeing industry, emphasizing that the modification of fabric is one of the best routes to improve the affinity between dye and fabric. ${ }^{9,10}$ The process of cross-linking plays an important role in the attachment of chitosan (biopolymer) to cotton fabric. Citric acid is an example of efficient cross-linking agent due to its versatile nature and to its safety for the environment and human health. ${ }^{11}$ It is biodegradable, economical, safe and a multipurpose chemical for sequestering, buffering, wetting, cleaning and dispersing. Thus, articulating the requirements for industrial application of sustainable chemistry, the use of citric acid in textile dyeing technologies can be a viable alternative. ${ }^{12}$

Chitosan is a versatile polycationic biopolymer derived from alkaline deacetylation of chitin. Chitosan exhibits several valuable inherent properties: it is antibacterial, antifungal, anti-viral, non-toxic, biodegradable and has film-forming characteristics. ${ }^{13}$ Chitosan possesses hydroxyl and amino functional groups, and can easily be fabricated with desired functional properties. ${ }^{14,15}$ It has been reported that chitosan can be used in the production of man-made fibres and in textile wet processing. It can be potentially utilized in dyeing to improve the dyeability, in finishing as antimicrobial agent and in printing as natural thickener in printing pastes. ${ }^{16}$

Keeping this in mind, in the present study, the chitosan biopolymer was selected as mordant for dyeing cotton fabric with natural dye (onion skin) to improve the dye absorption, without using metallic salts, and thus to achieve a safe and ecofriendly dyeing process.

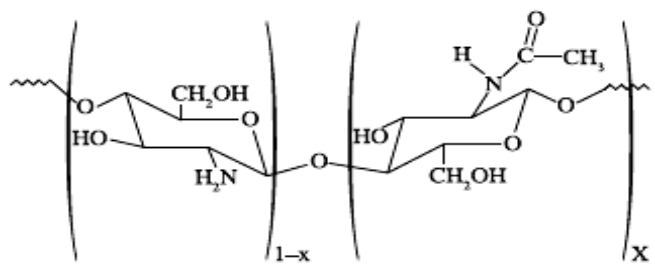

Figure 1: Structure of chitosan

\section{EXPERIMENTAL}

\section{Materials}

Pure cotton fabric was purchased from a local market in Hisar, Haryana. Chitosan was procured from Indian Sea Food Company, Cochin, Kerala. The citric acid, acetic acid and sodium hypophosphite were purchased from S.D. Fine-Chem Limited and HiMedia, a local supplier in Hisar (Rajesh Trading Company), respectively.

\section{Procedures}

\section{Enzymatic desizing and scouring}

The woven cotton fabric was subjected to desizing and scouring treatments to remove foreign materials before applying the finish.

The desizing treatment was performed using 2 $\mathrm{mL} / \mathrm{L}$ Americos Amylase 543 at $60{ }^{\circ} \mathrm{C}$ temperature for 60 minutes, with a 1:20 material to liquor ratio, maintaining a $\mathrm{pH}$ of 7 . The treatment liquor was drained out and the fabric was rinsed with hot and cold water, and then dried. ${ }^{17}$

Desized cotton fabric was scoured in a bath containing $1.5 \%$ (owf) Palkoscour APCL enzyme, at $60{ }^{\circ} \mathrm{C}$ for 60 minutes, at a material to liquor ratio of 1:15, maintaining a $\mathrm{pH}$ of 7.0. The fabric was rinsed with hot and cold water, and then dried. ${ }^{18}$

\section{Standardization of biopolymer treatment for natural dyeing}

Different parameters of biopolymer (chitosan) treatment were optimized to enhance the dyeing efficiency of cotton fabric towards the natural dye, on the basis of percent dye absorption, colour strength $(\mathrm{K} / \mathrm{S})$ value and wash fastness of treated and dyed samples. The following parameters were optimized: concentration of biopolymer, concentration of crosslinking agent, concentration of catalyst, $\mathrm{pH}$, material to liquor ratio, treatment time and temperature, curing time and temperature. 


\section{Natural dyeing of biopolymer treated cotton fabric}

The biopolymer treated cotton fabric was dyed with onion skin dye by the exhaust method, using the optimized dyeing parameters listed in Table 1.

\section{Percent dye absorption}

The percent dye absorption was calculated using the following formula:

$$
\begin{aligned}
\text { Percent dye absorption } & =\frac{\text { OD before dyeing }- \text { OD after dyeing }}{\text { OD before dyeing }} \times 100 \\
O D & =\text { Optical Density }
\end{aligned}
$$

\section{Colour measurement}

The colours of the dyed samples were measured numerically using a computerized colour matching machine. The reference spectra of the dyed samples were obtained using an SS5100A Spectrophotometer. The K/S value and CIE LAB co-ordinates $L^{*}$, $a^{*}$ and $\mathrm{b}^{*}$ were noted down directly from the computer screen.
This spectrophotometer uses the CIE LAB (1976) colour space, with D65 illuminate matching and appraisal, and the wavelength of $420 \mathrm{~nm}$ to measure the actual colour and changes in colour. The Kubelka Munk theory was used to predict the colour value:

$\mathrm{K} / \mathrm{S}=(1-\mathrm{R})^{2} / 2 \mathrm{R}$

\section{Assessment of fastness to washing of dyed fabrics}

The wash fastness test was carried out as per the recommendations of the IS: 3361-1979 method (BIS, 1979). The nine half-steps scale was used for fastness rating. A piece of original dyed sample and the test specimen were placed side by side in the same plane. The light was incident upon the surfaces at an approximate angle of $45^{\circ}$ and the direction of viewing was approximately perpendicular to the plane of the surface. The visual differences between the original and the tested material were compared, and the difference was represented on the grey scale.

Table 1

Optimized concentration/conditions for dyeing with onion skin dye

\begin{tabular}{lc}
\hline Dyeing parameters & $\begin{array}{c}\text { Optimized } \\
\text { concentration/conditions }\end{array}$ \\
\hline Dye concentration $(\%)$ & 6 \\
Dyeing pH & 5.5 \\
Dyeing temperature $\left({ }^{\circ} \mathrm{C}\right)$ & 90 \\
Dyeing time $(\min )$ & 75 \\
Dyeing material to liquor ratio & $1: 30$ \\
\hline
\end{tabular}
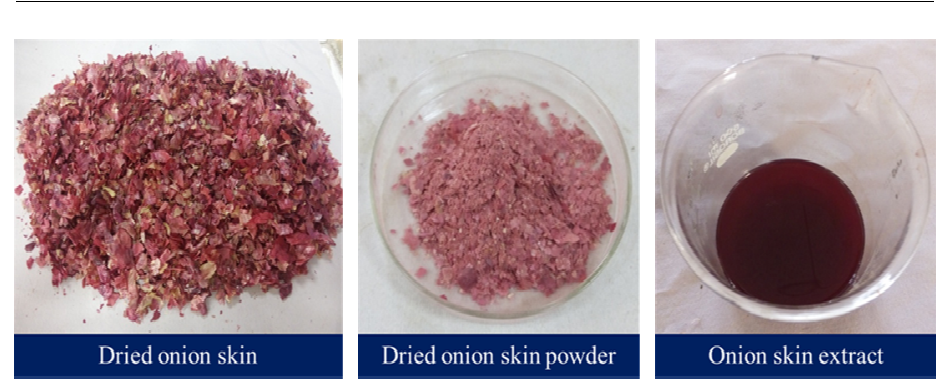

Figure 2: Onion skin dye

\section{Fourier transform infrared spectroscopy (FTIR) analysis}

Fourier transform infrared spectroscopy (FTIR) was carried out to characterize the biopolymer treated naturally dyed cotton fabric. The FTIR analysis of the fabrics was performed at SAIF, IIT Madras.

\section{RESULTS AND DISCUSSION Standardization of biopolymer treatment towards natural dyeing}

For standardization of the biopolymer (chitosan) treatment towards the natural dye (onion skin), different concentrations and conditions were optimized, as described below.

\section{Optimization of chitosan concentration}

For determining the optimum concentration of chitosan, five different concentrations, i.e. 1, 2, 3, 4 and 5 percent, were used and optimization was done on the basis of colour properties, i.e. dye absorption, colour strength and wash fastness. The data presented in Table 2 reveal that at 1.0 percent concentration of chitosan, the percent dye absorption was 60.71 , with colour strength $(\mathrm{K} / \mathrm{S})$ of 13.88 and wash fastness rating of 3/4.

As the concentration of chitosan increased from 1.0 to 5.0 percent, the $\mathrm{L}^{*}$ value decreased from 68.47 to 46.75 , indicating that colour darkness increased. The $\mathrm{a}^{*}$ value was found positive for all 
the chitosan concentrations, except that of 1 percent, which indicated that the dyed samples had a redder tone, except the sample dyed with 1 percent concentration, which had a greener tone. The $b^{*}$ value was positive for all the concentrations of chitosan, which showed a yellow tone. The $\mathrm{C}^{*}$ depicts the chroma value of the samples, which was highest (30.91) for the 2 percent chitosan treatment, followed by those of 5 (29.12), 4 (28.98), 1 (21.87) and 3 (21.85) percent. The hue angle $\left(\mathrm{H}^{*}\right)$ was below $90 \mathrm{o}$, with positive $\mathrm{a}^{*}$ and $\mathrm{b}^{*}$ values, depicting a brown and yellowish khaki colour of the sample for all concentrations of chitosan, whereas the $a^{*}$ value was negative, with a hue angle above 90 o at one percent concentration of chitosan, indicating a greenish khaki colour of the dyed sample. It is also clear from Table 2 that, as the concentration of chitosan increased from 1 to 5 percent, dye absorption also increased from 60.71 to 66.13 percent, and colour strength (K/S) - from 13.88 to 16.30. The wash fastness rating was fairly good (3/4) at 1 and 2 percent chitosan, whereas it was found good (4) at 3, 4 and 5 percent concentrations of chitosan. It was observed that there was no considerable difference in dye absorption, colour strength and wash fastness between the 4 and 5 percent concentrations of chitosan. Therefore, the 4 percent concentration of chitosan was selected as the optimum concentration for biopolymer treatment. These findings are supported by the results of Kittinaovarat, who reported that chitosan treated cotton fabric showed more functional groups (amino and methyl groups) than untreated cotton fabric.19 This is explained by the fact that chitosan provides more sites for the dye to attach and form functional hydrogen bonds, thus improving dyeing properties. Saravanan et al. also found that with the increase in the concentration of chitosan, the colour strength value of naturally dyed cotton fabric increased.20

\section{Optimization of cross-linking agent (citric acid) concentration}

Five concentrations of citric acid, i.e. 3, 4, 5, 6 and 7 percent, were tested for determining the optimum concentration of citric acid (Table 3 ). It was observed that 3 percent of citric acid, when applied with the optimized concentration of chitosan for the biopolymer treatment, led to a percent dye absorption of 60.12, a colour strength value of 11.53 and good (4) wash fastness rating. As the concentration of citric acid was increased from 3 to 7 percent, there was an increase in dye absorption from 60.12 to 64.35 percent, in colour strength - from 11.53 to 16.05 , with good (4) wash fastness rating. In addition, when the concentration of citric acid was increased from 3 to 7 percent, the $\mathrm{L}^{*}$ value decreased from 64.00 to 51.14 , depicting darkness of colour. The $\mathrm{a}^{*}$ and $b^{*}$ values were found positive for all the dyed samples, indicating redder and yellower tones, with different concentrations of citric acid in the biopolymer treatment. The $\mathrm{C}^{*}$ value, i.e. the chroma value, was highest (27.90) at 6 percent of citric acid concentration, followed by those of 5 (26.13), 3 (25.77), 7 (25.72) and 4 (25.45) percent. The hue angle $\left(\mathrm{H}^{*}\right)$ was below 900 , with positive $\mathrm{a}^{*}$ and $\mathrm{b}^{*}$ values for all the dyed samples, depicting brown and yellowish khaki colours of the samples. It is evident from Table 3 that, with the increase in citric acid concentration, the dye absorption and colour strength were enhanced, without affecting wash fastness. Also, the data reveal no considerable difference in dye absorption, colour strength and wash fastness of the dyed samples for the application of 6 and 7 percent concentration of citric acid. Therefore, the six percent concentration of citric acid was considered as optimum for the fixation of chitosan onto cotton fabric, leading to dye absorption of 64.35 percent, colour strength value of 16.05 and good wash fatness rating (4). To facilitate the attachment of natural dye, citric acid was used to create carboxylic acid functional groups on cotton fibers. Citric acid helps in the attachment of chitosan to cotton fabric through the cross-linking process. As the degree of cross-linking increases, the attachment of chitosan also increases, which attracts more anionic dye particles due to the cationic nature of chitosan. As a result, the dye absorption and colour strength of the fabric increased. These results are supported by the findings of Khattak et al., who stated that crosslinking was efficient in enhancing the colour strength and colour fastness of cotton fabric dyed with marigold. 21

\section{Optimization of catalyst concentration}

Sodium hypophosphite was selected as catalyst, along with the use of cross-linking agent, to facilitate the fixation of chitosan on the cotton fabric. Table 4 shows that five different concentrations of sodium hypophosphite, i.e. 2, 3, 4, 5 and 6 percent, were assessed for the optimization of catalyst concentration at the optimized ratio of chitosan and citric acid. 
Table 2

Optimization of chitosan concentration on the basis of colour properties of onion skin dyed fabric

\begin{tabular}{|c|c|c|c|c|c|c|c|c|}
\hline \multirow{2}{*}{$\begin{array}{c}\text { Chitosan concentration } \\
(\%)\end{array}$} & \multirow{2}{*}{$\begin{array}{c}\text { Dye absorption } \\
(\%)\end{array}$} & \multicolumn{5}{|c|}{ Colour coordinates } & \multirow{2}{*}{$\begin{array}{c}\text { Colour strength } \\
(\mathrm{K} / \mathrm{S})\end{array}$} & \multirow{2}{*}{$\begin{array}{c}\text { Wash fastnes } \\
\text { grades }\end{array}$} \\
\hline & & $\mathrm{L}^{*}$ & $\mathrm{a}^{*}$ & $\mathrm{~b}^{*}$ & $\mathrm{C}^{*}$ & $\mathrm{H}^{*}$ & & \\
\hline 1 & 60.71 & 68.47 & -0.219 & 21.87 & 21.87 & 90.61 & 13.88 & $3 / 4$ \\
\hline 2 & 62.50 & 57.38 & 13.49 & 27.81 & 30.91 & 64.09 & 13.77 & $3 / 4$ \\
\hline 3 & 64.88 & 51.92 & 15.46 & 15.44 & 21.85 & 44.95 & 15.77 & 4 \\
\hline 4 & 66.07 & 49.85 & 15.50 & 24.49 & 28.98 & 57.65 & 16.28 & 4 \\
\hline 5 & 66.13 & 46.75 & 16.36 & 24.09 & 29.12 & 55.79 & 16.30 & 4 \\
\hline
\end{tabular}

Table 3

Optimization of citric acid concentration on the basis of colour properties of onion skin dyed fabric

\begin{tabular}{|c|c|c|c|c|c|c|c|c|}
\hline \multirow{2}{*}{$\begin{array}{c}\text { Citric acid concentration } \\
(\%)\end{array}$} & \multirow{2}{*}{$\begin{array}{c}\text { Dye absorption } \\
(\%)\end{array}$} & \multicolumn{5}{|c|}{ Colour coordinates } & \multirow{2}{*}{$\begin{array}{l}\text { Colour strength } \\
(\mathrm{K} / \mathrm{S})\end{array}$} & \multirow{2}{*}{$\begin{array}{l}\text { Wash fastness } \\
\text { grades }\end{array}$} \\
\hline & & $\mathrm{L}^{*}$ & $a^{*}$ & $\mathrm{~b}^{*}$ & $\mathrm{C}^{*}$ & $\mathrm{H}^{*}$ & & \\
\hline 3 & 60.12 & 64.00 & 8.92 & 24.18 & 25.77 & 69.72 & 11.53 & 4 \\
\hline 4 & 61.90 & 59.27 & 10.22 & 23.30 & 25.45 & 66.28 & 12.85 & 4 \\
\hline 5 & 62.50 & 57.96 & 13.69 & 22.25 & 26.13 & 58.36 & 13.90 & 4 \\
\hline 6 & 64.29 & 54.78 & 14.97 & 23.54 & 27.90 & 57.51 & 16.03 & 4 \\
\hline 7 & 64.35 & 51.14 & 16.14 & 20.03 & 25.72 & 51.11 & 16.05 & 4 \\
\hline
\end{tabular}

Table 4

Optimization of sodium hypophosphite concentration on the basis of colour properties of onion skin dyed fabric

\begin{tabular}{|c|c|c|c|c|c|c|c|c|}
\hline \multirow{2}{*}{$\begin{array}{l}\text { Sodium hypophosphite } \\
\text { concentration }(\%)\end{array}$} & \multirow{2}{*}{$\begin{array}{c}\text { Dye absorption } \\
(\%)\end{array}$} & \multicolumn{5}{|c|}{ Colour coordinates } & \multirow{2}{*}{$\begin{array}{c}\text { Colour strength } \\
(\mathrm{K} / \mathrm{S})\end{array}$} & \multirow{2}{*}{$\begin{array}{c}\text { Wash fastness } \\
\text { grades }\end{array}$} \\
\hline & & $\mathrm{L}^{*}$ & $\mathrm{a}^{*}$ & $\mathrm{~b}^{*}$ & $\mathrm{C}^{*}$ & $\mathrm{H}^{*}$ & & \\
\hline 2 & 61.31 & 49.66 & 8.42 & 13.32 & 15.77 & 57.66 & 12.35 & $3 / 4$ \\
\hline 3 & 63.10 & 36.83 & 8.76 & 13.63 & 16.21 & 57.24 & 14.65 & $3 / 4$ \\
\hline 4 & 63.69 & 35.23 & 10.54 & 16.67 & 19.72 & 57.68 & 15.05 & 4 \\
\hline 5 & 64.17 & 34.08 & 10.60 & 19.08 & 21.83 & 60.91 & 15.83 & 4 \\
\hline 6 & 64.23 & 31.08 & 11.14 & 16.12 & 19.59 & 55.38 & 15.89 & 4 \\
\hline
\end{tabular}


When 2 percent concentration of sodium hypophosphite was applied along with the crosslinking agent and chitosan, followed by dyeing with onion skin, dye absorption was 61.31 percent, the colour strength value 12.35 and the wash fastness rating fairly good (3/4).

It is evident from the table that as the concentration of sodium hypophosphite increased from 2 to 6 percent, there was an increase in percent dye absorption from 61.31 to 64.23 , in colour strength (K/S) - from 12.35 to 15.89 , whereas the $L^{*}$ value decreased from 49.66 to 31.08, indicating higher darkness with a rising sodium hypophosphite concentration. The wash fastness rating of the dyed samples was good (4) with 4, 5, 6 percent concentration, whereas a fairly good (3/4) rating was noticed at 2 and 3 percent concentration. The $a^{*}$ and $b^{*}$ values were found positive for all the samples dyed with onion skin dye after biopolymer treatment, with different concentrations of sodium hypophosphite, which indicated that all the dyed samples had redder and yellower tones.

The chroma $\left(\mathrm{C}^{*}\right)$ value was higher $(21.83)$ at 5 percent concentration of catalyst, followed by 4 (19.72), 2 (15.77), 3 (16.21) and 6 (19.59) percent. The hue angle $\left(\mathrm{H}^{*}\right)$ was below $90^{\circ}$ with positive $\mathrm{a}^{*}$ and $\mathrm{b}^{*}$ values, depicting brown and yellowish khaki colours of the samples.

Five percent concentration of sodium hypophosphite was chosen as the optimum concentration, which allowed reaching a dye absorption value of 64.17 percent, colour strength of 15.83 and wash fatness rating (4), considering that there was no considerable difference in the colour properties of the dyed samples at 5 and 6 percent concentration of sodium hypophosphite. Vukusic et al. studied the finishing of cotton fabric with butane-tetracarboxylic acid and citric acid, along with sodium hypophosphite alone and in combination with phosphoric acid. It was observed that the sodium hypophosphite was the best catalyst for the fixation of chitosan onto cotton fabric. $^{22}$

\section{Optimization of pH for biopolymer treatment}

Five different $\mathrm{pH}$ values, i.e. 3, 4, 5, 6 and 7, were analysed for optimization. It is clear from Table 5 that when the $\mathrm{pH}$ of the treatment bath was maintained at 3 , the dyed fabric reached dye absorption of 60.12 percent, colour strength of 11.20 and fairly good (3/4) wash fastness rating.

As the $\mathrm{pH}$ of dye bath was increased from 3 to 5 , an enhancement in dye absorption from 60.12 to 61.90 percent, in colour strength from 11.20 to 14.45 and in wash fastness rating from fairly good (3/4) to good (4) was observed. However, further rise of the $\mathrm{pH}$ from 6 to 7 led to a decrease in dye absorption from 60.71 to 59.52 percent and colour strength from 9.71 to 8.65 , with fairly good (3/4) wash fastness rating. The $\mathrm{L}^{*}$ value decreased from 53.09 to 49.80 as the $\mathrm{pH}$ of the dye bath increased from 3.0 to 5.0, indicating increased darkness of shade, whereas an increased L* value, indicating reduced darkness of the samples, was noticed beyond $\mathrm{pH} 5$.

The $\mathrm{a}^{*}$ values were negative, but the $\mathrm{b}^{*}$ ones were positive at all the treatment $\mathrm{pHs}$, indicating the samples had greener and yellower tones. The chroma $\left(\mathrm{C}^{*}\right)$ value was higher $(8.92)$ at $\mathrm{pH}$ 5.0, followed by those at by 7 (7.82), 4 (7.55), 6 (6.67) and $3(6.51)$. The hue angle $\left(\mathrm{H}^{*}\right)$ was found between 91.37 and 115.30 , with negative $\mathrm{a}^{*}$ and positive $b^{*}$ values for all onion skin dyed samples, which depicted a greenish khaki colour of the samples. On the basis of the percent dye absorption (61.90), colour strength (14.45) and very good wash fastness rating, $\mathrm{pH} 5.0$ was selected as optimum for the bath formulation for the chitosan treatment. These findings are supported by Munna et al., who reported that the chitosan is insoluble in water, but soluble in dilute aqueous acidic solutions below its constant ( $\mathrm{pKa}$ ) $\sim 6.3$, wherein it is able to convert into the soluble protonated form $\left(-\mathrm{NH}_{3}\right){ }^{23}$ Rattanaphani et al. highlighted that the chitosan amino groups, $-\mathrm{NH}_{2}-$ would be in protonated cationic form $\left(-\mathrm{NH}_{3}{ }^{+}\right)$in acidic solution. After the pretreatment of cotton fabric with chitosan under acidic conditions, the protonated amino $\left(-\mathrm{NH}_{3}{ }^{+}\right)$groups of chitosan could interact with the surface of the cellulose. Chitosan could then act as an organic mordant to enhance the absorption of lac dye on the cellulose surface, resulting in dye sorption on cotton. ${ }^{24}$

\section{Optimization of material to liquor ratio for biopolymer treatment}

Different material to liquor ratios (owf) of the treatment bath used for biopolymer treatment, i.e. $1: 10,1: 20,1: 30$ and 1:40, were used for optimizing this parameter (M:L ratio). The data regarding the colour properties of onion skin dyed samples are presented in Table 6. It is evident from the table that at a 1:10 M:L ratio, a dye absorption of 60.71 percent, colour strength of 13.41, fairly good wash fastness rating (3/4) were recorded. As the $\mathrm{M}: \mathrm{L}$ ratio was increased from $1: 10$ to $1: 30$, the percent dye absorption also 
increased from 60.71 to 60.89 percent, the colour strength value - from 13.41 to 15.03 , and wash fastness rating - from fairly good (3/4) to good (4), whereas the $L^{*}$ value decreased from 68.93 to 68.01, which indicated darkness of colour. At 1:40 M:L ratio, a decrease in dye absorption and colour strength value was noticed, whereas the $\mathrm{L}^{*}$ value increased, which showed lightness of colour. The $a^{*}$ and $b^{*}$ values were positive at all the M:L ratios used for the chitosan treatment, which depicted that all the samples had a redder and yellower tone. The chroma $\left(\mathrm{C}^{*}\right)$ value was the highest (21.47) at a 1:30 M:L ratio, followed by those at 1:10 (21.36), 1:20 (20.88) and 1:40 (18.09). The hue angle $\left(\mathrm{H}^{*}\right)$ was found below $90 \mathrm{o}$ with positive $a^{*}$ and $b^{*}$ values, depicting brown and yellowish khaki colours of the samples.

It is apparent from the table that at the 1:30 $\mathrm{M}: \mathrm{L}$ ratio, the highest percent dye absorption (60.89), colour strength (15.03) and good wash fastness rating (4) were obtained, hence it was chosen as the optimum for the chitosan treatment on cotton fabric. This might be explained by the fact that for the complete wetting of fabric within the treatment bath, a sufficient amount of liquor (material to liquor ratio) is required. When the M:L ratio was too low, incomplete absorption of the finish within the fabric might have taken place. When the M:L ratio was too high, the hydrolysis rate would be higher, which would lead to decreased absorption of the finish and, as a result, poor attachment of chitosan. Thus, the absorption of dye onto fabric pretreated with chitosan above and below the sufficient M:L ratios would be low.

\section{Optimization of treatment temperature}

The samples were treated in the chitosan solution at five different temperatures, i.e. $60^{\circ}$, $70^{\circ}, 80^{\circ}, 90^{\circ}$ and $100{ }^{\circ} \mathrm{C}$, to optimize the treatment temperature for achieving the maximum dye absorption (Table 7).

The table elucidates that when the chitosan treatment was carried out at $60{ }^{\circ} \mathrm{C}$, dye absorption of 58.93 percent, colour strength of 8.01 and fairly good wash fastness rating (3/4) were achieved. When the samples were treated in the biopolymer solution at temperatures in the range from $60^{\circ}$ to $100{ }^{\circ} \mathrm{C}$, the dye absorption increased from 58.93 to 62.08 percent and colour strength from 8.01 to 14.83 , whereas the $\mathrm{L}^{*}$ value decreased from 60.03 to 49.73 , which indicated increased darkness of colour. A good (4) wash fastness rating was found for all the onion skin dyed samples pretreated with chitosan at different temperatures, except at $60{ }^{\circ} \mathrm{C}$. The $\mathrm{a}^{*}$ and $\mathrm{b}^{*}$ values were positive at all the treatment temperatures, which showed that all the samples had redder and yellower tones. The chroma value $\left(\mathrm{C}^{*}\right)$ was the highest $(26.88)$ at $90{ }^{\circ} \mathrm{C}$, followed by those at $80^{\circ}(24.99), 60^{\circ}(24.40), 70^{\circ}(22.46)$, and $100{ }^{\circ} \mathrm{C}(19.56)$. The hue angle $\left(\mathrm{H}^{*}\right)$ was below 90o, which depicted brown and yellowish khaki colours of samples.

For biopolymer treatment conducted at $90{ }^{\circ} \mathrm{C}$, dye absorption of 62.02 percent, colour strength of 14.75 and good wash fatness rating (4) were obtained, so this temperature was taken as the optimum treatment temperature, since there was no remarkable difference between the colour properties achieved at $90^{\circ}$ and $100{ }^{\circ} \mathrm{C}$ treatment temperature. This might be explained by the fact that a higher treatment temperature, with adequate duration of the treatment, facilitated the swelling of the fibre, which allowed an easy penetration and trapping of the chitosan finish into the fabric structure, resulting in increased dye absorption, colour strength and wash fastness rating.

The treatment time also played an important role in achieving the dye equilibrium, thus, the percent dye absorption increased until it reached equilibrium, then, hydrolysis of the dye started, which caused a decline in wash fastness and colour strength value because of lower dye absorption. Another reason could be that the dye deposited on fabric surface got hydrolysed, thus the wash fastness decreased.

\section{Optimization of treatment time}

The biopolymer treatment was performed with four different durations, i.e. 15, 30, 45 and 60 minutes. It can be noted from Table 8 that when the biopolymer treatment was carried out for 15 minutes, dye absorption of 58.33 percent, colour strength of 6.09 and fairly good wash fastness rating (3/4) were obtained.

As the duration of the biopolymer treatment was increased from 15 to 45 minutes, an increase in the dye absorption was noticed from 58.33 to 61.96 percent, in colour strength - from 6.09 to 14.45, whereas the $\mathrm{L}^{*}$ value decreased from 67.70 to 54.02, which means the darkness of shade increased. The wash fastness rating was found to be very good (4/5) for the 45 minute treatment, good (4) for 30 and 60 minutes, whereas it was fairly good (3/4) for the 15 minute treatment duration. 
Table 5

Optimization of treatment $\mathrm{pH}$ on the basis of colour properties of onion skin dyed cotton samples

\begin{tabular}{|c|c|c|c|c|c|c|c|c|}
\hline \multirow[t]{2}{*}{$\mathrm{pH}$} & \multirow{2}{*}{$\begin{array}{c}\text { Dye } \\
\text { absorption } \\
(\%)\end{array}$} & \multicolumn{5}{|c|}{ Colour coordinates } & \multirow{2}{*}{$\begin{array}{c}\text { Colour } \\
\text { strength } \\
(\mathrm{K} / \mathrm{S})\end{array}$} & \multirow{2}{*}{$\begin{array}{c}\text { Wash } \\
\text { fastness } \\
\text { grades }\end{array}$} \\
\hline & & $\mathrm{L}^{*}$ & $\mathrm{a}^{*}$ & $\mathrm{~b}^{*}$ & $\mathrm{C}^{*}$ & $\mathrm{H}^{*}$ & & \\
\hline 3 & 60.12 & 53.09 & -1.09 & 6.41 & 6.51 & 99.71 & 11.20 & $3 / 4$ \\
\hline 4 & 61.31 & 52.86 & -1.43 & 7.41 & 7.55 & 100.95 & 12.70 & 4 \\
\hline 5 & 61.90 & 49.80 & -3.81 & 8.07 & 8.92 & 108.95 & 14.45 & 4 \\
\hline 6 & 60.71 & 51.07 & -2.16 & 6.31 & 6.67 & 115.30 & 9.71 & $3 / 4$ \\
\hline 7 & 59.52 & 53.59 & -3.17 & 7.15 & 7.82 & 113.95 & 8.65 & $3 / 4$ \\
\hline
\end{tabular}

Table 6

Optimization of material to liquor ratio on the basis of colour properties of onion skin dyed cotton samples

\begin{tabular}{ccccccccc}
\hline \multirow{2}{*}{$\begin{array}{c}\text { M:L } \\
\text { ratio }\end{array}$} & $\begin{array}{c}\text { Dye } \\
\text { absorption } \\
(\%)\end{array}$ & $\mathrm{L}^{*}$ & $\mathrm{a}^{*}$ & $\mathrm{~b}^{*}$ & $\mathrm{C}^{*}$ & $\mathrm{H}^{*}$ & & $\begin{array}{c}\text { Colour } \\
\text { strength } \\
\end{array}$ \\
\cline { 3 - 8 } & & & & & $\begin{array}{c}\text { Wash } \\
\text { fastness } \\
\text { grades }\end{array}$ \\
\hline $1: 10$ & 60.71 & 68.93 & 10.06 & 18.84 & 21.36 & 61.86 & 13.41 & $3 / 4$ \\
$1: 20$ & 60.83 & 68.85 & 9.20 & 18.74 & 20.88 & 63.82 & 13.63 & 4 \\
$1: 30$ & 60.89 & 56.17 & 9.57 & 19.22 & 21.47 & 63.16 & 15.03 & 4 \\
$1: 40$ & 60.77 & 68.01 & 15.09 & 9.86 & 18.09 & 63.48 & 14.55 & $3 / 4$ \\
\hline
\end{tabular}

Table 7

Optimization of treatment temperature on the basis of colour properties of onion skin dyed cotton samples

\begin{tabular}{|c|c|c|c|c|c|c|c|c|}
\hline \multirow{2}{*}{$\begin{array}{l}\text { Treatment } \\
\text { temperature } \\
\left({ }^{\circ} \mathrm{C}\right)\end{array}$} & \multirow{2}{*}{$\begin{array}{c}\text { Dye } \\
\text { absorption } \\
(\%)\end{array}$} & \multicolumn{5}{|c|}{ Colour coordinates } & \multirow{2}{*}{$\begin{array}{l}\text { Colour } \\
\text { strength } \\
(\mathrm{K} / \mathrm{S})\end{array}$} & \multirow{2}{*}{$\begin{array}{c}\text { Wash } \\
\text { fastness } \\
\text { grades }\end{array}$} \\
\hline & & $\mathrm{L}^{*}$ & $a^{*}$ & $\mathrm{~b}^{*}$ & $\mathrm{C}^{*}$ & $\mathrm{H}^{*}$ & & \\
\hline 60 & 58.93 & 60.03 & 8.17 & 23.00 & 24.40 & 70.41 & 8.01 & $3 / 4$ \\
\hline 70 & 59.52 & 54.95 & 9.47 & 20.36 & 22.46 & 65.02 & 10.75 & 4 \\
\hline 80 & 61.90 & 51.76 & 14.41 & 20.41 & 24.99 & 54.76 & 14.15 & 4 \\
\hline 90 & 62.02 & 51.70 & 13.53 & 23.23 & 26.88 & 59.75 & 14.75 & 4 \\
\hline 100 & 62.08 & 49.73 & 6.11 & 23.34 & 19.56 & 50.19 & 14.83 & 4 \\
\hline
\end{tabular}

A slight decrease was noticed in percent dye absorption and colour strength with increasing treatment time (from 45 to 60 minutes). The $\mathrm{a}^{*}$ and $b^{*}$ values were positive for different durations of treatment time, showing redder and yellower tones of the samples. The chroma $\left(\mathrm{C}^{*}\right)$ was higher (26.38) at 45 minute duration of the treatment, followed by those at 60 (18.03), 15 (17.64) and 30 (17.17) minutes. The hue angle $\left(\mathrm{H}^{*}\right)$ was found below 900 with positive $a^{*}$ and $b^{*}$ values, which indicated brown and yellowish khaki colours of the samples. It is clear from the table that at 45 minutes of chitosan treatment, the highest percent dye absorption (61.96), colour strength (14.45) and wash fastness rating (4/5) were observed, hence this duration was considered as the optimum treatment time.
Optimization of curing temperature

The effect of curing temperature on the chitosan treated fabric, cured at five different temperatures, i.e. $110^{\circ}, 120^{\circ}, 130^{\circ}, 140^{\circ}$ and $150{ }^{\circ} \mathrm{C}$, is presented in Table 9. When the curing of the chitosan treated sample was carried out at $110{ }^{\circ} \mathrm{C}$, the onion skin dye absorption reached 60.77 percent, with colour strength of 14.84 and good (4) wash fastness rating. It is clear from the table that the increase in curing temperature from $110^{\circ}$ to $150{ }^{\circ} \mathrm{C}$ led to enhanced dye absorption from 60.77 to 64.88 percent and colour strength from 14.84 to 15.79 , whereas the $L^{*}$ value decreased from 50.56 to 46.62 , which showed increased darkness of colour. The wash fastness rating of the dyed samples was good (4) at $110^{\circ}, 120^{\circ}, 130$ ${ }^{\circ} \mathrm{C}$ and very good (4/5) at $140^{\circ}$ and $150{ }^{\circ} \mathrm{C}$ curing 
temperature. The $\mathrm{a}^{*}$ and $\mathrm{b}^{*}$ values were found to be positive for all the curing temperatures, showing redder and yellower tones. The chroma $\left(\mathrm{C}^{*}\right)$ was the highest $(24.96)$ at $150{ }^{\circ} \mathrm{C}$ curing temperature, followed by that at $130^{\circ}$ (24.94), $140^{\circ}$ (24.67), $110^{\circ}$ (24.08), and $120^{\circ} \mathrm{C}(23.84)$. The hue angle $\left(\mathrm{H}^{*}\right)$ was below 90 o with positive $a^{*}$ and $b^{*}$ values for all the onion skin dyed samples, which depicted brown and yellowish khaki colours. It is obvious from the table that there was no considerable difference in dye absorption, colour strength and wash fastness observed between $140^{\circ}$ and $150{ }^{\circ} \mathrm{C}$ curing temperature. Therefore, $140{ }^{\circ} \mathrm{C}$ was taken as the optimum curing temperature for the chitosan treated fabric for further dyeing with onion skin natural dye. At this curing temperature, dye absorption of 64.29 percent, colour strength of 15.74 and very good $(4 / 5)$ wash fatness rating were achieved. The findings of the study are supported by those of Aly et al., who reported that the fixation of chitosan increased with increasing curing temperature and time, establishing that 150 ${ }^{\circ} \mathrm{C}$ curing temperature with 5 minute curing time were optimum for providing antibacterial property. ${ }^{25}$

\section{Optimization of curing time}

The results related to curing of chitosan treated cotton fabric, carried out at four different durations, i.e. 1, 2, 3 and 4 minutes, are presented in Table 10. At 1 minute duration of curing, the dye absorption was 62.50 percent, colour strength -14.43 and the wash fastness rating - good (4). It can be noticed from the table that, as the duration of the curing was increased from 1 to 4 minutes, the dye absorption increased from 62.50 to 65.54 percent and colour strength - from 14.43 to 15.44 , whereas the $\mathrm{L}^{*}$ value decreased from 60.55 to 53.14 , denoting increased darkness of colour. The wash fastness rating was found good (4) at all curing times, except for the sample cured for 4 minutes, which showed very good (4/5) wash fastness rating.

All the dyed samples cured for different durations of time after the chitosan treatment had positive $a^{*}$ and $b^{*}$ values, indicating redder and yellow tones. The chroma $\left(\mathrm{C}^{*}\right)$ was the highest (15.19) at 2 minutes duration of curing, followed by that at 3 (15.01), 1 (14.28) and 4 (9.58) minutes. The hue angle $\left(\mathrm{H}^{*}\right)$ was found below $90^{\circ}$, having positive $a^{*}$ and $b^{*}$ values, indicating brown and yellowish khaki colours of the samples.

It is visible from the table that the highest dye absorption (65.54\%), colour strength (15.44) and wash fastness rating (4/5) were recorded at 4 minutes duration of curing, hence this values was taken as the optimum curing time. These results are in agreement with those of Mohanraj et al., who used leaf extract for treatment of cotton fabric using 8 percent citric acid by the pad dry cure method; the samples were dried at $100^{\circ}-105$ ${ }^{\circ} \mathrm{C} .{ }^{26}$

Table 8

Optimization of treatment time on the basis of colour properties of onion dyed cotton fabric

\begin{tabular}{|c|c|c|c|c|c|c|c|c|}
\hline \multirow{2}{*}{$\begin{array}{l}\text { Treatment } \\
\text { time } \\
\text { (min) }\end{array}$} & \multirow{2}{*}{$\begin{array}{c}\text { Dye absorption } \\
(\%)\end{array}$} & \multicolumn{5}{|c|}{ Colour coordinates } & \multirow{2}{*}{$\begin{array}{c}\text { Colour } \\
\text { strength } \\
(\mathrm{K} / \mathrm{S})\end{array}$} & \multirow{2}{*}{$\begin{array}{c}\text { Wash } \\
\text { fastness } \\
\text { grades }\end{array}$} \\
\hline & & $\mathrm{L}^{*}$ & $a^{*}$ & $\mathrm{~b}^{*}$ & $\mathrm{C}^{*}$ & $\mathrm{H}^{*}$ & & \\
\hline 15 & 58.33 & 67.70 & 6.90 & 16.23 & 17.64 & 66.92 & 6.09 & $3 / 4$ \\
\hline 30 & 60.71 & 64.52 & 9.60 & 14.24 & 17.17 & 55.95 & 9.28 & 4 \\
\hline 45 & 61.96 & 54.02 & 12.32 & 23.32 & 26.38 & 62.10 & 14.45 & $4 / 5$ \\
\hline 60 & 61.90 & 56.63 & 9.21 & 15.51 & 18.03 & 59.27 & 14.41 & 4 \\
\hline
\end{tabular}

Table 9

Optimization of curing temperature on the basis of colour properties of onion skin dyed cotton fabric

\begin{tabular}{|c|c|c|c|c|c|c|c|c|}
\hline \multirow{2}{*}{$\begin{array}{c}\text { Curing } \\
\text { temperature } \\
\left({ }^{\circ} \mathrm{C}\right)\end{array}$} & \multirow{2}{*}{$\begin{array}{c}\text { Dye } \\
\text { absorption } \\
(\%)\end{array}$} & \multicolumn{5}{|c|}{ Colour coordinates } & \multirow{2}{*}{$\begin{array}{c}\text { Colour } \\
\text { strength } \\
(\mathrm{K} / \mathrm{S})\end{array}$} & \multirow{2}{*}{$\begin{array}{c}\text { Wash } \\
\text { fastness } \\
\text { grades }\end{array}$} \\
\hline & & $\mathrm{L}^{*}$ & $\mathrm{a}^{*}$ & $\mathrm{~b}^{*}$ & $\mathrm{C}^{*}$ & $\mathrm{H}^{*}$ & & \\
\hline 110 & 60.77 & 50.56 & 10.34 & 21.75 & 24.08 & 64.55 & 14.84 & 4 \\
\hline 120 & 60.95 & 48.88 & 10.73 & 21.28 & 23.84 & 63.20 & 14.90 & 4 \\
\hline 130 & 63.10 & 48.84 & 12.56 & 21.55 & 24.94 & 59.73 & 15.31 & 4 \\
\hline 140 & 64.29 & 46.94 & 12.29 & 21.39 & 24.67 & 60.09 & 15.74 & $4 / 5$ \\
\hline 150 & 64.88 & 46.62 & 12.93 & 21.34 & 24.96 & 58.75 & 15.79 & $4 / 5$ \\
\hline
\end{tabular}


Table 10

Optimization of curing time on the basis of colour properties of onion skin dyed cotton fabric

\begin{tabular}{|c|c|c|c|c|c|c|c|c|}
\hline \multirow{2}{*}{$\begin{array}{l}\text { Curing } \\
\text { time } \\
(\mathrm{min})\end{array}$} & \multirow{2}{*}{$\begin{array}{c}\text { Dye } \\
\text { absorption } \\
(\%)\end{array}$} & \multicolumn{5}{|c|}{ Colour coordinates } & \multirow{2}{*}{$\begin{array}{l}\text { Colour } \\
\text { strength } \\
(\mathrm{K} / \mathrm{S})\end{array}$} & \multirow{2}{*}{$\begin{array}{c}\text { Wash } \\
\text { fastness } \\
\text { grades }\end{array}$} \\
\hline & & $\mathrm{L}^{*}$ & $a^{*}$ & $\mathrm{~b}^{*}$ & $\mathrm{C}^{*}$ & $\mathrm{H}^{*}$ & & \\
\hline 1 & 62.50 & 60.55 & 0.90 & 14.25 & 14.28 & 86.33 & 14.43 & 4 \\
\hline 2 & 63.69 & 59.76 & 0.69 & 15.17 & 15.19 & 87.34 & 14.96 & 4 \\
\hline 3 & 65.48 & 59.37 & 1.43 & 14.94 & 15.01 & 84.50 & 15.28 & 4 \\
\hline 4 & 65.54 & 53.14 & 5.75 & 7.66 & 9.58 & 53.06 & 15.44 & $4 / 5$ \\
\hline
\end{tabular}

Table 11

Optimum conditions for biopolymer treatment of cotton towards onion skin dyeing

\begin{tabular}{cc}
\hline Treatment parameters & Optimized condition \\
\hline Concentration of chitosan $(\%)$ & 4.0 \\
Concentration of citric acid $(\%)$ & 6.0 \\
Concentration of sodium hypophosphite $(\%)$ & 5.0 \\
$\mathrm{pH}$ & 5.0 \\
Material to liquor ratio & $1: 30$ \\
Treatment temperature $\left({ }^{\circ} \mathrm{C}\right)$ & 90 \\
Treatment time $(\min )$ & 45 \\
Curing temperature $\left({ }^{\circ} \mathrm{C}\right)$ & 140 \\
Curing time $(\min )$ & 4 \\
\hline
\end{tabular}

It was remarked that, with increasing curing temperature and time, the dye absorption and colour strength values increased. The reason might be that, for maximum cross-linking, high temperature is required. During curing, high temperature was provided to chitosan treated fabric for sufficient time, which increased the rate of the cross-linking reaction and facilitated the fixation of chitosan within the cotton fabric. The chitosan attachment provided cationic character to cotton fabrics and attracted more dye molecules, as a result the dye absorption and colour strength value of the fabric increased.

\section{Application of chitosan on cotton fabric}

Chitosan was applied on scoured cotton fabric through pad dry cure method using optimized parameters as presented in Table 11 for biopolymer treatment process. Cotton fabric was first impregnated in a solution containing optimum concentrations of chitosan (4\%), citric acid $(6 \%)$ and sodium hypophosphite (5\%), keeping a 1:30 material to liquor ratio at $\mathrm{pH} 5$, the treatment was performed at $90{ }^{\circ} \mathrm{C}$ for 45 minutes. The impregnated fabric was pressed between the squeezing rollers of the padding mangle machine, maintaining the pressure of $2 \mathrm{~kg} / \mathrm{cm}$ and achieving $70 \%-75 \%$ expressions. The treated samples were dried at $100{ }^{\circ} \mathrm{C}$ for 5 minutes and cured for 4 minutes at $140{ }^{\circ} \mathrm{C}$ before dyeing with onion skin dye.

\section{FTIR analysis}

The FTIR analysis of the chitosan treated onion skin dyed fabric was performed and the peak assignments shown in Table 12 indicated the presence of different functional groups in the fabric structure.

Table 12

FTIR peak assignments for chitosan treated onion skin dyed cotton fabric

\begin{tabular}{cccc}
\hline $\begin{array}{c}\text { S. } \\
\text { No. }\end{array}$ & $\begin{array}{c}\text { Peak ranges } \\
\left(\mathrm{cm}^{-1}\right)\end{array}$ & Peaks & Functional groups \\
\hline 1. & $3200-3300$ & 3273.69 & $\begin{array}{c}\text { Hydroxyl group (H-bonded-OH- stretching) } \\
2 .\end{array}$ \\
$2800-2900$ & 2895.77 & C-H stretching, O-H stretching - alkanes (CH; CH2; \\
& & & CH3), carboxylic acids \\
3. & $2200-2300$ & 2294.82 & Cyanocompounds, disubstituted alkynes \\
4. & $2100-2200$ & 2106.81 & C-triple bond-C-stretching \\
5. & $1600-1700$ & 1631.14 & Functional group C=O, -C-double bond-C stretch \\
6 & $1400-1500$ & 1426.68 & Organic sulphates \\
\hline
\end{tabular}




\begin{tabular}{cccc}
\hline 7. & $1300-1400$ & 1363.39 & -OH bending \\
& & 1313.75 & Aromatic amino stretch \\
8. & $1200-1300$ & 1202.53 & Tertiary amine, -CN- stretch \\
9. & $1100-1200$ & 1105.67 & Secondary amine -CN- stretch \\
& & 1153.05 & \\
10. & $1000-1100$ & 1026.76 & -C-C- stretch \\
11 & $700-800$ & 703.07 & Skeletal -C-C- vibrations \\
12. & $600-700$ & 664.19 & Aliphatic bromo-compounds \\
& & 610.67 & -C-I- stretching \\
\hline
\end{tabular}

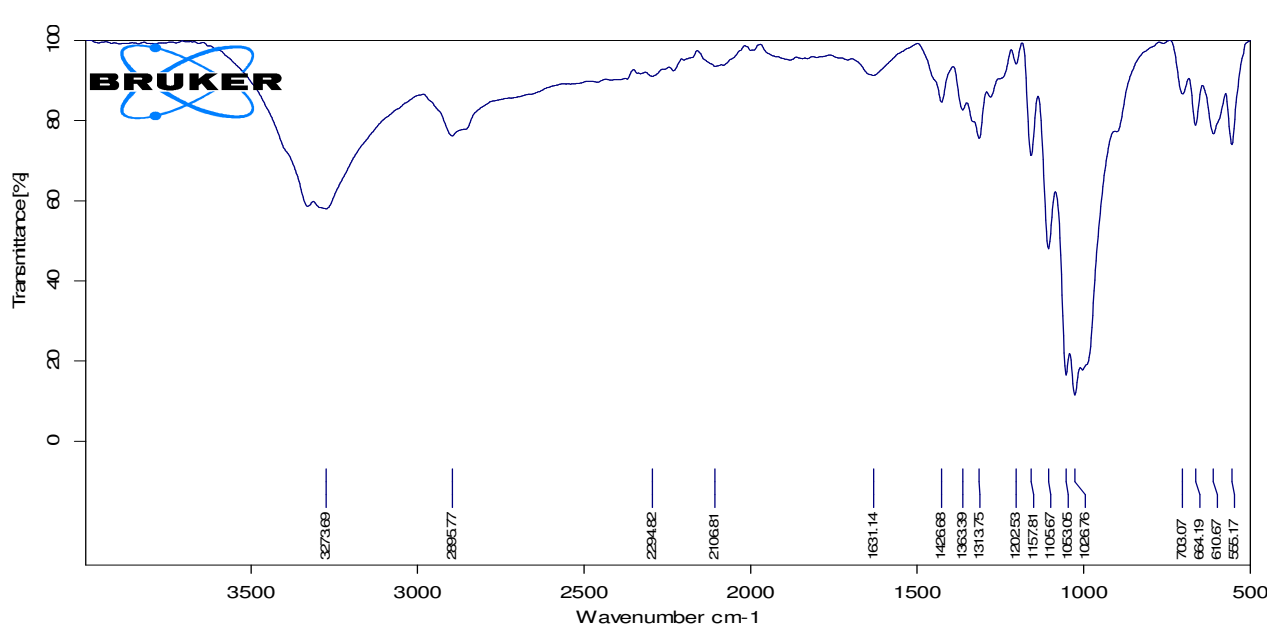

Figure 3: FTIR spectrum of chitosan treated onion skin dyed cotton fabric

The peaks at $3273.69 \mathrm{~cm}^{-1}, 2895.77 \mathrm{~cm}^{-1}$, $2294.82 \mathrm{~cm}^{-1}, 2106.81 \mathrm{~cm}^{-1}$ and $1631.14 \mathrm{~cm}^{-1}$ are associated with the presence of hydroxyl groups (Hbonded $\mathrm{OH}$ stretching), $\mathrm{C}-\mathrm{H}$ stretching, $\mathrm{O}-\mathrm{H}$ stretching (alkanes, carboxylic acids), cyanocompounds, $\mathrm{C}$-triple bond $\mathrm{C}$-stretching and functional groups $\mathrm{C}=\mathrm{O}$, -C-double bond-C stretch, respectively. This confirmed the existence of different functional groups, viz. organic sulphates $\left(1426.68 \mathrm{~cm}^{-1}\right),-\mathrm{OH}$ bending and aromatic amino stretching $\left(1363.39 \mathrm{~cm}^{-1}\right.$ and $\left.1313.75 \mathrm{~cm}^{-1}\right)$, tertiary amine and $-\mathrm{CN}$ - stretch $\left(1202.53 \mathrm{~cm}^{-1}\right)$, secondary amine $-\mathrm{CN}$ - stretch $\left(1105.67 \mathrm{~cm}^{-1}, 1153.05 \mathrm{~cm}^{-1}, 1157.81 \mathrm{~cm}^{-1}\right),-C-$ C- stretch $\left(1026.76 \mathrm{~cm}^{-1}\right)$, skeletal -C-Cvibrations $\left(703.07 \mathrm{~cm}^{-1}\right)$, aliphatic bromo compounds $\left(664.19 \mathrm{~cm}^{-1}\right.$ and $\left.610.67 \mathrm{~cm}^{-1}\right)$, -C-Istretch $\left(555.17 \mathrm{~cm}^{-1}\right)$. According to Hollen and Saddler, the chemical reactivity of cellulose is related to three hydroxyl groups ( $\mathrm{OH}$ groups) of the glucose unit. These groups readily react with moisture, dyes, and many finishes. ${ }^{27}$ FTIR analysis of chitosan treated cotton fabric indicated the presence of amine groups $\left(\mathrm{NH}_{2}\right)$, which are the active sites for many chemical reactions. It revealed that the chitosan imparted its cationic character to the cotton fabric and provided more cationic sites for the attachment of the anionic dye. The chitosan treatment imparted secondary amine and tertiary amine characteristics to cotton fabric, which provided maximum dye exhaustion, because under acidic conditions, the secondary and tertiary groups got more protonated and attracted more anionic dye.

\section{CONCLUSION}

The optimum conditions for the biopolymer treatment on cotton fabric were found as follows: $4 \%$ chitosan concentration, $6 \%$ citric acid and 5\% sodium hypophosphite, $\mathrm{pH} 5.0$ and a M:L ratio of 1:30. The biopolymer treatment was applied to scoured fabric by the pad dry cure method, using $90{ }^{\circ} \mathrm{C}$ treatment temperature for 45 minutes. For the fixation of chitosan on the cotton fabric, the curing was done at optimized temperature (140 ${ }^{\circ} \mathrm{C}$ ) and time (4 min). FTIR analysis of the chitosan treated onion skin dyed fabric confirmed the presence of different functional groups responsible for increasing the dyeing efficiency of cotton fabric. It was noticed that, at the optimized concentrations and conditions, the biopolymer treatment led to higher dye absorption, colour 
strength and wash fastness grade of the naturally dyed cotton. The optimized chitosan treatment enhanced the dyeing efficiency and provided very good wash fastness to cotton fabric, without using any salts or electrolytes. Thus, such a pretreatment makes the dyeing process more ecofriendly, safe and involving lower production costs and waste generation.

ACKNOWLEDGEMENT: The authors would like to thank the Department of Textile and Apparel Designing of Home Science, CCS, HAU Hisar, for providing guidance, and DST, Govt. of India, for providing funding support through the Inspire Fellowship.

\section{REFERENCES}

P. Samanta, D. Singhee and A. K. Samanta, Curr. Trends Fashion Technol. Textile Eng., 2, 69 (2018), https://doi.org/10.19080/CTFTTE.2018.02.555593

2 D. Jothi, Autex Res. J., 8, 49 (2008), http://www.autexrj.com/contact/

3 R. G. Manipon, Int. J. Innov. Technol. Explor. Eng., $\quad 8, \quad 55 \quad$ (2019), https://doi.org/10.100486S319/19/BEIESP

4 A. Khan, A. Ahmad, M. I. Khan, M. Yusuf, M. Shahid et al., Dyes Pigments, 95, 206 (2012), https://doi.org/10.1016/j.dyepig.2012.04.010

D. Cristea and G. Vilarem, Dyes Pigments, 70, 238 (2006), https://doi.org/10.1016/J.DYEPIG.2005.03.006

6 A. Khan, M. Khan, P. K. Srivastava and F. Mohammad, Colourage, 53, 61 (2006)

7 Md. R. Repon, M. T. Islam and Md. A. Al Mamun, Chem. Mater. Eng., 4, $39 \quad$ (2016), https://doi.org/10.13189/CME.2016.040302

8 M. D. Teli, J. Sheikh and P. Shastrakar, J. Text., 2013, ID $320510 \quad$ (2013), https://doi.org/10.1155/2013/320510

9 M. Sundrarajan, A. Rukmani, R. R. Gandhi and S. Vigneshwaran, J. Chem. Pharm. Res., 4, 1654 (2012), https://www.jocpr.com/archive/jocpr-volume-4-issue3-year-2012.html

10 A. Şahan and A. Demir, Procs. XIII ${ }^{\text {th }}$ International Izmir Textile and Apparel Symposium, April 2-5, 2014

11 O. Adeoye, A. Lateef and E. B. Gueguim-Kana, Biocatal. Agric. Biotechnol., 4, 568 (2015), https://doi.org/10.1016/j.bcab.2015.08.004
12 R. Angumeenal and D. Venkappayya, Food Sci. Technol., $\quad \mathbf{5 0 ,} \quad 370 \quad$ (2013), https://doi.org/10.1016/j.lwt.2012.05.016

13 J. P. Venter, A. F. Kotze, R. Auzely-Velty and M. Rinauda, Int. J. Pharm. Sci. Res., 313, 36 (2006), https://doi.org/10.1016/j.ijpharm.2006.01.016

14 K. Dutta, J. Dutta and V. S. Tripathi, J. Sci. Ind. Res., $\quad 63, \quad 20 \quad$ (2004), http://nopr.niscair.res.in/handle/123456789/5397

15 S. Pokhrel, P. N. Yadav and R. Adhikari, Nepal J. Sci. Technol., $\quad$ 16, $99 \quad$ (2015), https://doi.org/10.3126/njst.v16i1.14363

16 D. Gupta and A. Haile, Carbohyd. Polym., 69, 164 (2007), https://doi.org/10.1016/j.carbpol.2006.09.023

17 C. Vigneshwaran, M. Ananthasubramanian, N. Anbumani and P. Kandhavadivu, J. Eng. Fiber. Fabr., 8, $121 \quad$ (2013), https://doi.org/10.1177/155892501300800215

18 K. Rajendran, Sundaram, R. Radhar and P. Rajapriya, Pak. J. Biol. Sci., 14, 519 (2011), https://doi.org/10.3923/pjbs.2011.519.525

19 S. Kittinaovarat, J. Sci. Res., 29, 155 (2004)

20 P. Saravanan, G. Chandramohan, J. Mariajancyrani and P. Shanmugasundaram, Int. Res. J. Environ. Sci., 2 ,

http://www.isca.in/IJENS/Archive/v2/i12/1.ISCAIRJEvS-2013-221.pdf

21 S. P. Khattak, S. Rafique, T. Hussain and B. Ahmad, Life Sci. J., 11, 52 (2014), https://doi.org/10.14233/ajchem.2015.19245

22 B. Vukusic and D. Katovic, in Procs. AATCC Int. Conf. \& Exh., Winston-Salem, N.C., USA, September, 17-19, 2000, https://www.bib.irb.hr/4551

23 K. H. Munna, A. C. Chinyerenwa, Kamruzzaman, A. Hossain, K. Ahamed et al., Int. J. Text Sci., 6, 1 (2017), https://doi.org/10.5923/j.textile.20170601.01

24 S. Rattanaphani, M. Chairat, J. Bremner and V. Rattanaphani, Dyes Pigments, 72, 88 (2007), https://doi.org/10.1016/j.dyepig.2005.08.002

25 A. S. Hashem, A. Hussein and S. Sayed, Indian J. Fibre Text. Res., 29, $218 \quad$ (2004), https://www.niscair.res.in

26 S. Mohanraj, P. Vanathi, N. Sowbarniga and D. Sararanan, Indian J. Fibre Text. Res., 37, 389 (2012), https://www.niscair.res.in

${ }_{27}$ R. Hollen and J. Saddler, "Textiles", Macmillan, New York Publications, New York, USA, 1979, pp. 132 